\title{
The Pacific Ocean and global OBIS: a New Zealand perspective
}

Dennis P. Gordon

National Institute of Water \& Atmospheric Research (NIWA) - Wellington New Zealand

\section{Introduction}

New Zealand is the most oceanic nation of significant size, in the world's largest ocean. It is more than $1600 \mathrm{~km}$ from the nearest continent, has a land area of 268,200 $\mathrm{km}^{2}$ (103,552 square miles), and a very large Exclusive Economic Zone (EEZ), almost 4.2 million $\mathrm{km}^{2}$, that spans $30^{\circ}$ of latitude and exceeds fifteen times the land area (Figure 1). This large sea area constitutes both a huge resource reservoir and a huge challenge to a country with only 3.8 million people. And, although the scales vary, similar challenges exist for the many small Pacific Island states with EEZs vastly exceeding land areas. The Ocean Biogeographical Information System (OBIS) and Census of Marine Life (CoML) concepts have particular appeal to New Zealand oceanographers and fisheries

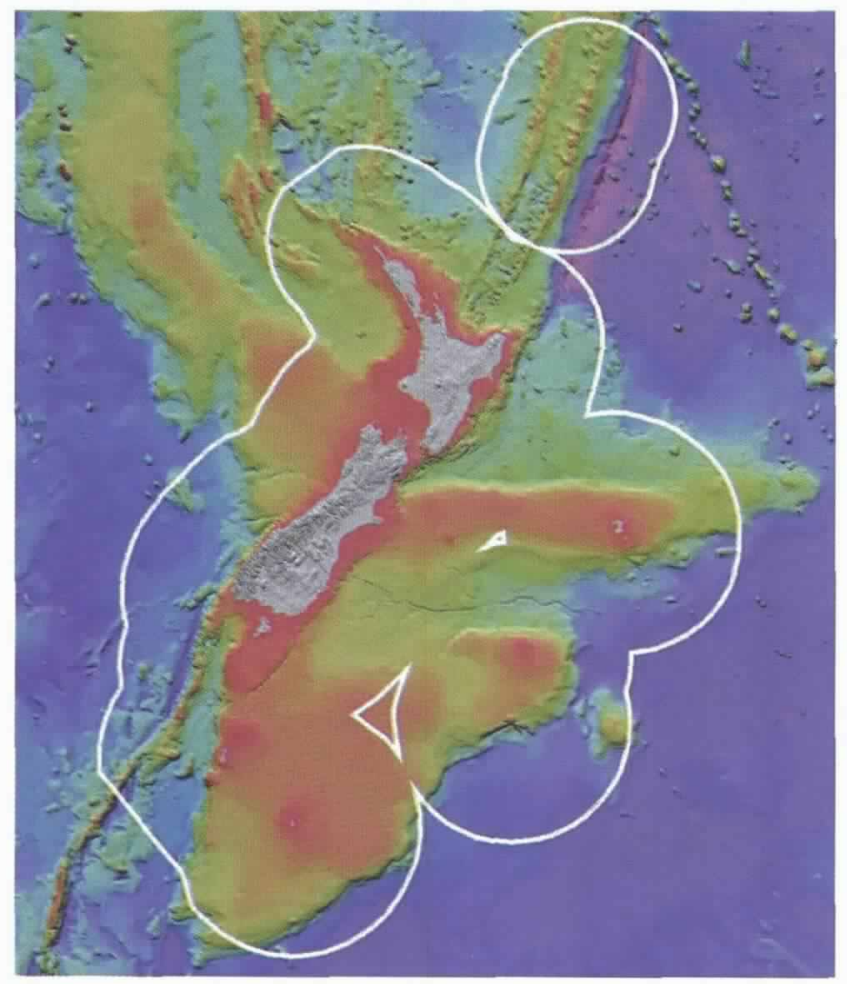

Figure 1. Undersea New Zealand, showing major seafloor features - continental shelves, plateaus, ridges, trenches, and the deep sea floor - and the boundary of the 200 nautical mile EEZ. Figure courtesy of the CANZ Group, NIWA.

scientists who are in the process of developing regional equivalents that can also link with the global system. Here, I review New Zealand's ocean information systems, current challenges and constraints, and the potential to contribute to a global OBIS/CoML, in the context of the Pacific Ocean.

\section{NIWA - a one-stop data shop}

One positive consequence of New Zealand's small population base is the concentration of ocean-exploration resources in one main organization. This is the National Institute of Water \& Atmospheric Research (NIWA), one of nine Crown Research Institutes that emerged in 1992 from a restructuring of government science. Today it is New Zealand's second-largest

\section{TABLE I}

Number of NIWA data sources for biological distributions, 196I-present.

Method

Fisheries trawls

Bottom trawls

Midwater trawls

Non-fish trawls

Plankton net

Ichthyoplankton

Non-fish plankton

Dredge

Grab

Core

Shore collection

Sediment trap

Scuba

Epibenthic sled

Other

TOTAL
Count

27,315

24,101

3,214

I,785

5,578

3,478

2,100

5,709

4,305

3,162

1,869

89 


\begin{tabular}{|c|c|}
\hline \multicolumn{2}{|c|}{$\begin{array}{l}\text { TABLE } 2 \\
\text { Number of Ministry of Fisheries } \\
\text { data sources for commercial fish and squid } \\
\text { catch-effort data, 1989-present. Data earlier } \\
\text { than } 1989 \text { are not yet in an available format. }\end{array}$} \\
\hline Method & Count \\
\hline Bottom longline & 236,595 \\
\hline Bottom pair trawl & 13,233 \\
\hline Beach seine & 19,982 \\
\hline Bottom trawl & 829,556 \\
\hline Cod pot & 60,402 \\
\hline Dredge & 88,557 \\
\hline Diving & 56,928 \\
\hline Dahn lines & 18,209 \\
\hline Drift net & 5,217 \\
\hline Danish seine & 21,324 \\
\hline Eel pots & 17,112 \\
\hline Fyke nets & 87,828 \\
\hline Fish pot & 33,348 \\
\hline Hand gathering & 49,578 \\
\hline Handline & 6,820 \\
\hline Midwater pair trawl & 81 \\
\hline Midwater trawl & 235,330 \\
\hline Pole lines & 686 \\
\hline Purse seine & 8,667 \\
\hline Rock lobster pot & 469,146 \\
\hline Ring net & 15,096 \\
\hline Surf cast net & 27 \\
\hline Squid jig & 31,832 \\
\hline Surface longline & 36,631 \\
\hline Set net & 341,790 \\
\hline Troll & 80,482 \\
\hline Trot lines & 4,448 \\
\hline Other & 8,417 \\
\hline Total & $2,777,322$ \\
\hline
\end{tabular}

research organization (after AgResearch), with approximately 600 staff, comprising oceanographic, fisheries, atmospheric, and freshwater scientists. This fruitful mix allows for the full range of multidisciplinary studies needed to investigate land-sea, seafloor-ocean, and ocean-atmosphere interactions. NIWA maintains several core databases including the Freshwater Fish Database, National Climate Database, and Hydrometric Database, and manages for the Ministry of Fisheries a large, diverse Fisheries Database and extensive acoustic-survey database. Of particular relevance to OBIS is the core database of the former N.Z. Oceanographic Institute (established in 1954 and subsumed by NIWA in 1992). This includes base data (station identifier, date, depth, gear) for about 66,000 benthic and midwater stations, mostly in the New Zealand EEZ but also in the surrounding ocean from the Cook Islands to the Ross Sea. More than 10,000 of these are benthic and sediment stations of which 4471 include both kinds of samples. Collectively, data types include benthic, planktonic/midwater, sediment/geology, and physical oceanographic. Ancillary data include taxa recorded or collected, sediment type, seafloor temperature, and water properties (e.g. salinity, conductivity-temperature-depth), depending on the type and purpose of cruise. A number of cruises also yielded bottom photographs, acoustic images, and seismic profiles. Tables 1 through 3 give the number and type of data sources for marine biological distributions and ancillary physical data held by or managed by NIWA.

The Biology Database contains specimen records (predominantly invertebrates) from seafloor sampling programs initiated in the early 1960s. The quality of the data is very variable, owing to the level in the taxonomic hierarchy at which organisms were identi-

\begin{tabular}{|c|c|}
\hline \multicolumn{2}{|c|}{$\begin{array}{c}\text { TABLE 3 } \\
\text { Number of NIWA data sources } \\
\text { for ancillary physical information, 196I-present. }\end{array}$} \\
\hline Method & Count \\
\hline CTD & 6,135 \\
\hline Hydrocast & 3,092 \\
\hline Photo & 2,387 \\
\hline Acoustic image & \\
\hline Seismic profile & \\
\hline Water sample & 1,897 \\
\hline Sediment sample & \\
\hline Core & 4,868 \\
\hline Drill & 1,706 \\
\hline Other & 3,162 \\
\hline Sonobuoy & $|, 54|$ \\
\hline Bathythermograph & 339 \\
\hline TOTAL & 20,259 \\
\hline
\end{tabular}

fied (species to phylum!) and the taxonomic skill of the observer. There are also base-data transcription errors and spelling mistakes in species names that need correcting. Out of more than 120,000 invertebrate distributional records, 56,827 are for genera and 47,112 are for species. The sampling of the New Zealand non-vertebrate marine biota is still inadequate. Despite the density of benthic sampling stations achieved (now more than 10,000), the total area of seafloor sampled scientifically by trawls, dredges, epibenthic sleds, grabs, corers (but excluding SCUBA) is only about $1.5 \mathrm{~km} 2$. [The addition of museum and university records to this figure would still total less than $2 \mathrm{~km} 2$ - about one twomillionth of the area of the EEZ.] Approximately $80 \%$ of all such sampling has been carried out in the $0-1000 \mathrm{~m}$ 


\section{TABLE 4}

NIWA data on seamount features in the New Zealand EEZ and extra-territorial sea. Seamounts are defined as having a vertical elevation $>100 \mathrm{~m}$. Numbers are regarded as minimum estimates. Depth is based on depth at base of seamount.

Number in EEZ
No. with area data
Area $\left(\mathrm{km}^{2}\right)$
No. fished ( $>5$ tows)
No. extraterritorial

\begin{tabular}{c}
$\leq 750 \mathrm{~m}$ \\
\hline 11 \\
7 \\
2,233 \\
3 \\
2
\end{tabular}

\begin{tabular}{c}
$750-1250 m$ \\
\hline 126 \\
88 \\
1,647 \\
101 \\
7
\end{tabular}

\begin{tabular}{c}
$1250-2500 \mathrm{~m}$ \\
\hline 119 \\
104 \\
8,067 \\
38 \\
29
\end{tabular}

\begin{tabular}{c}
$>2500 \mathrm{~m}$ \\
\hline 133 \\
131 \\
88,460 \\
3 \\
248
\end{tabular}

\begin{tabular}{c} 
TOTAL \\
\hline 389 \\
330 \\
100,407 \\
145 \\
286
\end{tabular}

depth range, which is $28 \%$ of the sea-surface area of the EEZ (Nelson and Gordon, 1997).

Thanks to five decades of accumulated bathymetric data, and more recent GPS satellite navigation, swath mapping, and satellite altimetry, it has been possible to quickly ascertain from the NIWA database how many seamount features occur in the EEZ and local extra-territorial waters, their height above the seafloor, and their area (Table 4). This information has provided the background for a research program focusing on the biology of seamounts. There is considerable fishing pressure (for orange roughy, Hoplostethus atlanticus, and oreos, Oreosomatidae) on a number of seamounts, and underwater photographs of damaged coral plus collections of large and old coral specimens gives evidence of potential for significant negative impacts. Remote videography, already underway, is allowing censusing of biota on selected seamounts in the EEZ (Clark et al., 2000).

The Fisheries Database includes Ministry and NIWA research trawl-survey data (>24,000 trawls, 1961-1999) and industry catch records (Table 2). The research trawlsurveys were conducted to determine fish and squid distribution, abundance, changes, and diversity, and cover most areas of the EEZ, from about 5 to $1500 \mathrm{~m}$ depth (Figure 2). The data are analyzed to determine the distribution of species, the types and composition of fish communities, their changes in distribution and abundance over time, and whether these changes might be related to environmental fluctuations or fishing activity. Three atlases showing the distribution of the most frequently caught demersal, midwater, and pelagic species have been published (Anderson et al., 1998; Hurst et al., 2000; Bagley et al., 2000) and information in the database has been used to address the following questions: 1) Can discrete fish communities be identified in the New Zealand region?; 2) Do fish communities have distinct boundaries or do they merge into each other?; 3) Are the distributions of fish species and communities determined by physical factors such as depth and temperature? Pelagic species are also included in the database, based on aerial sightings by pilots working with purse-seine vessels. Since 1976, more than
52,000 sightings have been made from northern North Island to the mid-South Island, with data recorded on about 100 species. Single-species schools provide the best information on distribution. Current and future work will include more detailed analyses of subsets of the data. Data include prawn trawl records, as well as length-frequency and feeding data for fish and squid. The range of environmental variables associated with

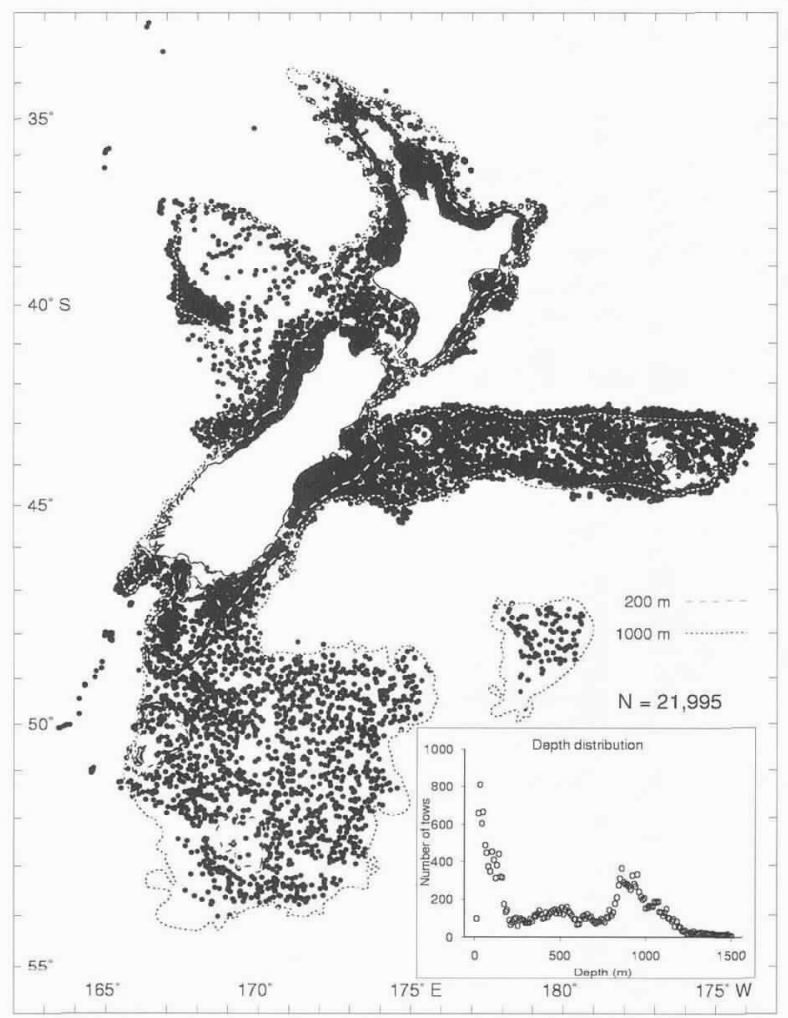

Figure 2: Location and depth of 21,995 bottom trawls in the NIWA Fish Communities Database, 1961-1997. Currently, the database represents more than 24,000 bottom trawls, recording $>335,000$ occurrences of 634 species. The trawl sites selected for the figure comprise those that were successful in yielding fish and squid for the database. This database is sourced from New Zealand Ministry of Fisheries data managed by NIWA. Figure courtesy of Owen Anderson, NIWA. 


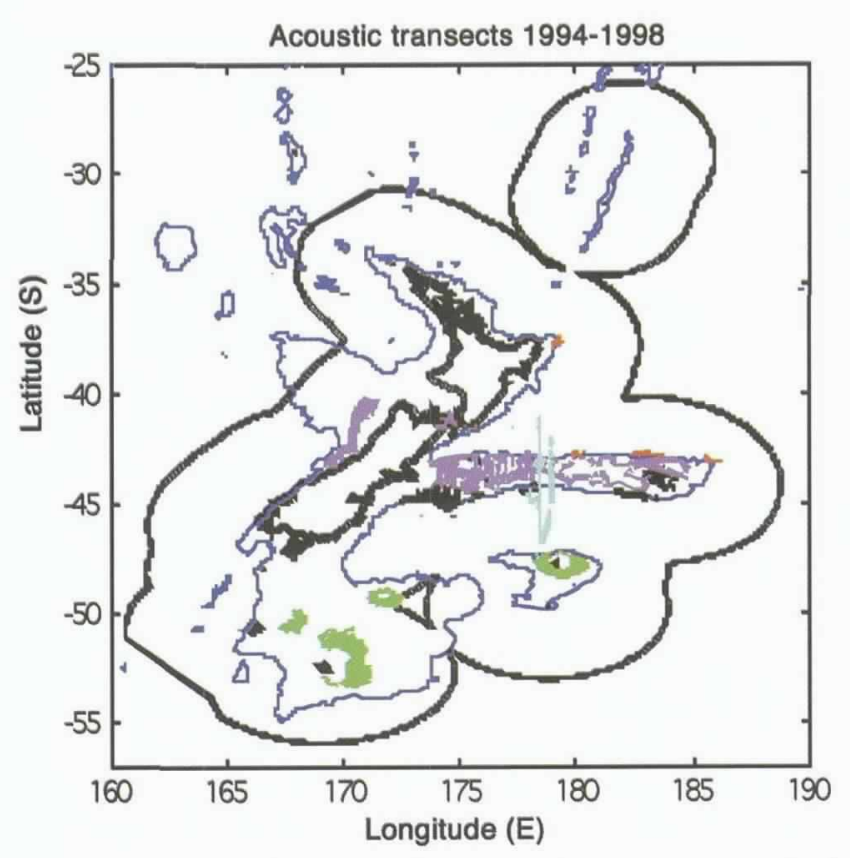

Figure 3: Example of the regional coverage of acoustic transects in the NIWA acoustic database. Purple transects = hoki surveys, black transects = orange roughy and oreos, green transects = southern blue whiting, lightblue transects = oceanographic research. The solid black line is the boundary of the EEZ. Blue lines indicate the 1,000 m contour. Figure courtesy of Dr. S. McClatchie, NIWA.

fish distribution will be extended to include salinity, water masses, thermoclines, sediments, and ocean color. This will enable investigation of pelagic and midwater communities, identify areas of juvenile and adult distribution and abundance, examine community structure at finer spatial and temporal scales, and determine general feeding relationships.

NIWA also manages large datasets from acoustic surveys conducted between 1987-2000 around New Zealand. Regional coverage is focussed on areas supporting commercial fisheries for hoki (Macruronus novaezelandiae), orange roughy (Hoplostethus atlanticus), oreos (Oreosomatidae), and southern blue whiting (Micromesistius australis), but considerable data are also available from oceanographic voyages on the Chatham Rise (Figure 3). The acoustic database stores the raw acoustic data (both phase and amplitude) to facilitate processing for species discrimination or calculation of biomass estimates as acoustic target strength relationships are refined. The database includes both single beam and split beam data from a variety of frequencies including 3.5, 12, 38, and $120 \mathrm{kHz}$. Acoustic data are stored in conjunction with navigational information, which facilitate comparison of acoustic and extensive trawl catch data that often accompanies biomass surveys (such as catch by species and or number, size by species and ancillary biological information). A database of echograms characteristic of specific epi-benthic and mid-water fish species is being compiled. Ongoing studies at NIWA are using modelling of scattering from different fish species to design new broad-band acoustic
TABLE 5

How many species in the sea?

\begin{tabular}{|c|c|c|c|}
\hline \multirow[b]{2}{*}{ Group } & \multicolumn{2}{|c|}{ New Zealand } & \multirow{2}{*}{$\begin{array}{c}\text { Global } \\
\text { Described }\end{array}$} \\
\hline & Described & $\begin{array}{c}\text { Known } \\
\text { unreported/ } \\
\text { undescribed }\end{array}$ & \\
\hline Protista + Fungi & 2,010 & 95 & 24,540 \\
\hline Seaweeds + plants & 687 & 78 & 5,970 \\
\hline Sponges & 410 & 255 & 5,000 \\
\hline Hydroids, corals, etc. & 572 & 395 & 7,025 \\
\hline Comb jellies & 13 & 6 & 80 \\
\hline Flat worms, etc. & 155 & 90 & 6,795 \\
\hline Bryozoans & 600 & 310 & 5,700 \\
\hline Entoprocts & 9 & 5 & 150 \\
\hline Ribbon worms & 18 & 6 & 1,250 \\
\hline Annelid worms & 497 & 244 & 8,335 \\
\hline Molluscs & 3,588 & 1,174 & 32,890 \\
\hline Lamp shells & 30 & 0 & 405 \\
\hline Arrow worms & 18 & 1 & 100 \\
\hline Round worms & 130 & 60 & 4,200 \\
\hline Crustaceans, etc. & 2,009 & 381 & 33,780 \\
\hline Sea-stars, etc. & 588 & 160 & 6,150 \\
\hline Acorn worms, etc. & 4 & 1 & 90 \\
\hline Sea squirts, salps, etc. & 187 & 50 & 1,300 \\
\hline Fish, marine mammals & $1,2 \mid 2$ & 140 & 13,845 \\
\hline All other groups & 48 & 23 & ।,705 \\
\hline Totals & 12,785 & 3,435 & 159,310 \\
\hline
\end{tabular}

\begin{tabular}{|lrrrr|}
\hline \multicolumn{5}{|c|}{ TABLE 6} \\
New Zealand's marine species diversity \\
Group & $\begin{array}{c}\text { Described } \\
\text { species }\end{array}$ & $\begin{array}{c}\text { Known } \\
\text { unrecorded } \\
\text { species }\end{array}$ & $\begin{array}{c}\text { Estimated } \\
\text { unknown } \\
\text { species }\end{array}$ & $\begin{array}{c}\text { Totals } \\
\text { rounded }\end{array}$ \\
Protista, Algae, & & 173 & $\begin{array}{r}1,200- \\
2,100\end{array}$ & $\begin{array}{r}4,070- \\
4,970\end{array}$ \\
Fungi, Plants & 2,697 & & $4,320-$ & $16,320-$ \\
Invertebrates & 8,876 & 3,122 & 5,440 & 17,440 \\
Vertebrates & 1,212 & 140 & 160 & 1,510 \\
Totals & 12,785 & $\mathbf{3 , 4 3 5}$ & $\mathbf{5 , 6 8 0 - 7 0 0}$ & $\mathbf{2 1 , 9 0 0 -}$ \\
\hline
\end{tabular}

systems to improve discrimination of species such as orange roughy and oreos (Barr, in press).

\section{A National Biodiversity Information System}

In 1999, a team of NIWA scientists proposed the development of a National Aquatic Biodiversity Information Strategy (NABIS) (Glasby et al., 1999). 
Through the NABIS we envisage that "All of the available data on New Zealand's freshwater and marine biodiversity is digitally archived for future security and made accessible to stakeholders through an integrated system of databases in order to improve the under- standing, sustainable utilization and management of our aquatic environments." The initial focus - to develop a marine benthic information strategy and concurrently upgrade NIWA's marine benthic database - was broadened to include and integrate freshwater biodiversity

TABLE 7

Summary of major challenges facing New Zealand and Pacific Island nations in marine biodiversity assessment, living marine resources inventory, and censusing of marine life. And some possible solutions.

CHALLENGES
The sampling challenge
- Large size of $200 \mathrm{~nm}$ EEZ
- Small population (i.e. human resource) base
- High cost of ocean survey and sampling
$\quad$ grgency (because of anthropogenic impacts) including
global warming

The taxonomic challenge

- shortage (or lack) of specialists for most taxonomic groups

- urgency (because of aging practitioners, little training, and few new recruits and jobs)

- validation of shipboard identifications yet to be carried out for many species records

\section{SOLUTIONS}

The sampling challenge

- increased use of remote technologies and partnerships with key technological agencies

- increased quantitative sampling of selected areas of seafloor (including the deep sea) and of smaller meiobenthic faunas

- application of marine BioRap* procedures for rapid assessment of assemblages in priority areas in relation to sediment and hydrographic factors and map their distributions

The taxonomic challenge

- publication of more and varied identification products

- baseline review of all known taxa (cf. Species 2000: NZ)

- development of national taxonomic strategies

- increase in capacity-building and training of new recruits for regional initiatives
Data and analytical challenges

- biodiversity data mainly non-quantitative presenceabsence type

- many biodiversity data not yet captured electronically

- many biodiversity data not yet, or only partly analyzed (e.g. identifications to family or genus only, few cluster analyses to ascertain relationships in assemblages)

- many ancillary data (e.g. sediments) not yet digitized

- existing databases need upgrading to accommodate new information fields and to permit linkages
Data and analytical challenges

- development of national or regional biodiversity information systems (cf. NIWA's newly formulated strategy NABIS-National Aquatic Biodiversity Information System) and/or linkage with OBIS/CoML

- upgraded database systems, based on international standard(s)

- increased rate of capture of biodiversity data from published and unpublished sources to databases

- digitization of untransformed ancillary data

- conformity to data standards
Policy challenges

- too many disparate agencies and pieces of legislation relating to the marine environment

- often no clear hierarchy of responsibility or effective mechanism for protecting marine biodiversity, either incountry or for extra-territorial waters

- no cohesive strategy or timetable for marine-protected areas
Policy challenges

- development of national and regional ocean policies

- simplification of the complex legislation and management structures and increased international cooperation

- development of national and regional strategies and timetables for protection of marine areas

- willingness of national and international agencies to increase support for ocean science (which should include biodiversity studies and database upgrading)

The educational challenge

- increased education about marine conservation values to all citizens

- more reviews and syntheses of available scientific data and their communication to all potential users of the information 
TABLE 8

The areal biodiversity and data-management challenge - Pacific Ocean EEZs in relation to land area and population base (adapted from SPREP 1999).

\begin{tabular}{|c|c|c|c|c|}
\hline State/Territory & Land area $\mathrm{km}^{2}$ & $E E Z$ area $\mathrm{km}^{2}$ & $\begin{array}{c}\text { EEZ vs land area } \\
\text { (times larger, rounded) }\end{array}$ & Population \\
\hline American Samoa & 197 & 390,000 & 1980 & 57,000 \\
\hline Cook Islands & 180 & $1,830,000$ & 10,167 & 18,100 \\
\hline Fiji & 18,376 & $1,290,000$ & 70 & 768,700 \\
\hline French Polynesia & 3,521 & $5,030,000$ & 1,429 & 221,300 \\
\hline Guam & 549 & 218,000 & 397 & 150,000 \\
\hline Kiribati & 727 & $3,550,000$ & 4,883 & 80,400 \\
\hline Marshall Islands & 720 & $2,131,000$ & 2,960 & 56,500 \\
\hline Micronesia (Fed. States) & 702 & $2,978,000$ & 4,242 & 125,100 \\
\hline Nauru & 21 & 320,000 & 15,238 & 10,400 \\
\hline New Caledonia & 19,103 & $1,740,000$ & 91 & 186,800 \\
\hline New Zealand & 268,200 & $4,199,100$ & 16 & $3,800,000$ \\
\hline Niue & 258 & 390,000 & 1,512 & 2,200 \\
\hline Northern Marianas & 475 & $1,823,000$ & 3,838 & 71,800 \\
\hline Palau & 500 & 629,000 & 1,258 & 16,900 \\
\hline Papua New Guinea & 461,690 & $3,120,000$ & 7 & $4,173,200$ \\
\hline Pitcairn & 5 & 800,000 & 160,000 & 50 \\
\hline Samoa & 2,934 & 120,000 & 41 & 163,900 \\
\hline Solomon Islands & 29,785 & $1,340,000$ & 45 & 375,000 \\
\hline Tokelau & 12 & 290,000 & 24,167 & 1,600 \\
\hline Tonga & 696 & 700,000 & 1,006 & 98,900 \\
\hline Tuvalu & 26 & 900,000 & 34,615 & 9,900 \\
\hline Vanuatu & 12,189 & 680,000 & 56 & 168,300 \\
\hline Wallis \& Futuna & 124 & 300,000 & 2,419 & 14,700 \\
\hline Total & 820,989 & $34,768,100$ & & $10,570,800$ \\
\hline
\end{tabular}

data and associated aquatic environmental information from all potential providers in New Zealand (including museums, marine laboratories, Regional Councils, and Department of Conservation conservancy offices). The NABIS will be developed and implemented over the next several years in three phases: 1) Database development/preparation for networking within New Zealand; 2) Web-based integration and interrogation, i.e., integrating New Zealand marine benthic databases with those of museums and oceanographic institutes in Europe and North America for mutual interrogation using standard data-interchange protocols; 3) Modeling and estimating biodiversity in relation to environmental variables and human activities.

Much information on coastal and shallow-shelf non-fish species records in New Zealand - species lists, distribution maps, and relative abundance estimates is contained in student theses, unpublished reports, and published literature. One of the goals of the NABIS strategy is to make these data available electronically and to improve standardization of data protocols (e.g. locality, depth, species, and time periods). These data will feed into another NIWA project, which is to map the benthos of the EEZ. Very little of the New Zealand seafloor has been sampled quantitatively but the high density of sampling in some areas may be adequate to allow the use of presence-absence data in characterizing species distributions and the identification of benthic assemblages. These will be mapped, area by area, over the continental shelf and eventually into the deep sea. The picture that emerges, at alpha, beta, and gamma levels, will be helpful in a number of ways. Knowing the distribution of species and assemblages over the wider region will give an objective measure for deciding what and where to protect, and what criteria to use, e.g. representativeness, genetic or habitat rarity, ecological attributes, resource potential, etc. Knowledge of species and assemblages will provide opportunities to identify large-scale distributional trends, biodiversity hotspots, and areas for more detailed study, e.g. 
transitional areas, areas under fronts, areas of economic interest, or subject to environmental/anthropogenic perturbations.

\section{Biodiversity and other challenges - and some solutions}

Among the challenges facing New Zealand, and especially the small island states of the Pacific, is biodiversity inventory, especially in deeper water which is subject to exploitation but which has not been intensively sampled or characterized scientifically. A species inventory of the entire New Zealand biota, known as Species 2000: New Zealand, is providing a snapshot of biodiversity at the turn of the century. A five-day symposium in February 2000 featured kingdom- and phylum-by-phylum reviews of knowledge to date, and chapters will shortly be collated into a volume to be published in 2001 (International Biodiversity Observation Year - IBOY). Interim estimates of marine species richness in Tables 5 and 6 suggest that, at the present rate of discovery and formal recording of new species and records, it will take at least a century to finish the task of marine inventory. Tallies for New Zealand marine species (EEZ) in Table 5 are summarized in the first two columns of Table 6, which also gives conservative estimates of undiscovered species in column three. The totals of 9,115 to 11,135 for columns two and three combined are estimates of the numbers of species yet to be formally recorded or described. At the present rate of reporting additions to our marine biota (<100 species per year), it will take another 90 to 110 years to complete the task. Certainly the rate of discovery of new taxa (e.g. one new fish species/record per fortnight) exceeds the ability of the New Zealand taxonomic community to keep abreast of it (Gordon, in press). We are finding, as we receive fresh bycatch from observers on commercial fishing vessels in deep water $(>1000 \mathrm{~m})$, that species previously thought to be rare are commoner than we thought. At the same time, many new species are being found, some quite spectacular. The discouraging aspect is that the fishing methods yielding the new taxa are very likely severely impacting the habitats from which they are taken.

There are numerous other challenges to achieving New Zealand and Pacific Island contributions to an OBIS and Census of Marine Life. These, and some suggested solutions, are summarized in Table 7. Many Pacific Island nations have ratified the 1992 Convention on Biological Diversity or are signatory to it and, while all have very large EEZs in relation to their land area (Table 8), integrated coastal (and ocean) management (ICM) are only now beginning to gain attention in many of them (SPREP, 1999). Partnerships are the only way most Pacific Island countries will be able to inventory, document, and benefit from biodiversity information, using common data standards and architecture. Fortunately, regionalism is an important characteristic of the Pacific Islands. There are a number of intergovernmental agencies and NGOs helping Pacific Island nations deal with ICM problems, especially those that are of such scale that they can only be dealt with on a multi-country basis. OBIS and CoML are concepts that have great appeal and potential for the island nations of the world's largest ocean who, however, will need technical and financial assistance for reciprocal benefits.

\section{REFERENCES}

Anderson, O.F., N.W. Bagley, R.J. Hurst, M.P. Francis, M.R. Clark and P.J. McMillan, 1998: Atlas of New Zealand fish and squid distributions from research bottom trawls. NIWA Technical Report, 42, 1-303.

Bagley, N.W., O.F. Anderson, R.J. Hurst, M.P. Francis, P.R. Taylor, M.R. Clark and L.J. Paul, 2000: Atlas of New Zealand fish and squid distributions from midwater trawls, tuna longline sets, and aerial sightings. NIWA Teclunical Report, 72, 1-171.

Barr, $R$, In press: A design study of an acoustic system suitable for differentiating between orange roughy and other New Zealand deep-water species. J. of the Acoust. Soc. of Am.

Clark, M., S. O'Shea, B. Wood and I. Wright, 2000: Seamount management: a report on seamounts potentially suitable for considerable under MFish seamount management strategy. NIWA Client Report, WLG 00-33, 1-79.

Glasby, C.J., N.P. Ching, D.P. Gordon and D.A. Robertson, 1999: Strategy for the development of a National Aquatic Biodiversity Information System (NABIS). NIWA Client Report, WLG 99-36, 1-29 + 4 appendices.

Hurst, R.J., N.W. Bagley, O.F. Anderson, M.P. Francis, L.H. Griggs, M.R. Clark, L.J. Paul and P.R. Taylor, 2000: Atlas of juvenile and adult fish and squid distributions from bottom and midwater trawls and tuna longlines in New Zealand waters. NIWA Technical Report, 84, 1-162.

Nelson, W.A. and D.P. Gordon, 1997: Assessing New Zealand's marine biological diversity - a challenge for policy makers and systematists. Nero Zealand Sci. Rev., 54, 58-66.

South Pacific Regional Environment Programme, 1999: Coastal Management Profiles: A Directory of Pacific Island Governments and non Government Agencies with Coastal Management Related Responsibilities. SPREP, Apia, 205 pp.

Ward, T.J., R.A. Kenchington, D.P. Faith and C.R. Margules, 1998: Marine BioRap Guidelines: Rapid Assessment of Marine Biological Diversity. CSIRO, Perth, $52 \mathrm{pp}$. 